\title{
PERSPECTIVAS DAS PESQUISAS EM GERONTOLOGIA E GERIATRIA: REVISÃO DA LITERATURA ${ }^{1}$
}

\author{
Maria Célia de Freitas ${ }^{2}$ \\ Sônia Ayako Tao Maruyama ${ }^{3}$ \\ Terezinha de Freitas Ferreira ${ }^{4}$ \\ Ana Maria de Almeida Motta ${ }^{5}$
}

Freitas MC, Maruyama SAT, Ferreira TF, Motta AMA. Perspectivas das pesquisas em gerontologia e geriatria: revisão da literatura. Rev Latinoam Enfermagem 2002 março-abril; 10(2):221-8.

Este estudo é exploratório e descritivo e objetivou identificar e analisar as tendências e perspectivas das pesquisas nas áreas de gerontologia e geriatria. Realizou-se levantamento bibliográfico, junto ao Banco de Dados Lilacs e acervo da Escola de Enfermagem de Ribeirão Preto-USP, de publicações multiprofissionais, no período de 1980 a 2000. Apresentaram-se os resultados sob a forma de tabelas e gráficos, destacando-se os estudos com enfoque geriátrico (54\%). Quanto às abordagens, houve, na última década (1990 a 2000), aumento, distribuindo-se em Biológica (32\%), Recursos Humanos (18\%), Social (17\%), Psicológica (9,8\%), Holística (4,0\%), excetuando-se a Ética que permaneceu com o mesmo percentual nos dois períodos (0,8\%). Em relação ao tipo de pesquisa, predominou a qualitativa (49,2\%). Verificase, portanto, que as perspectivas em relação aos idosos indicaram interesse dos profissionais pela temática, tanto pelas transições demográficas e epidemiológicas quanto pela formação de recursos humanos, para o mundo do trabalho junto a idosos, no âmbito profissional e no domiciliar.

DESCRITORES: gerontologia, geriatria, pesquisa

\section{PERSPECTIVES OF RESEARCH IN GERONTOLOGY AND GERIATRICS}

This exploratory descriptive study aimed at identifying and analyzing the tendencies and perspectives regarding research in the areas of gerontology and geriatrics. Initially, authors completed a bibliographical review of the Lilac's Data Bank and publications from 1980 to 2000 found at the University of São Paulo at Ribeirão Preto College of Nursing Library. Authors presented the results in tables and graphs, emphasizing the studies on geriatrics - 54\%. Regarding the approach, authors found, in the last decade (1990 to 2000), an increase of studies in the areas of Biology (32\%), Human Resources (18\%), Social (17\%), Psychology (9,8\%), Holism (4,0\%), excepting Ethics that remained with the same rate in both periods $(0,8 \%)$. With respect to the research type, the qualitative ones were predominant $(49,2 \%)$. Thus, authors concluded that there is an increasing interest of professionals in the area due to the demographic and epidemiological transitions and also regarding the capacitation of human resources to work with the elderly.

DESCRIPTORS: gerontology, geriatrics, research

\section{PERSPECTIVAS DE LA INVESTIGACIÓN EN GERONTOLOGÍA Y GERIATRÍA}

Estudio exploratorio descriptivo, que buscó identificar y analizar las tendencias y perspectivas en relación con la investigación en las áreas de gerontología y geriatría. Se realizó un levantamiento bibliográfico utilizando el Banco de Datos LILACS y el acervo de la Escuela de Enfermería de Ribeirão Preto/USP de publicaciones multiprofesionales en el periodo de 1980 a 2000. Se presentaron los resultados en tablas y gráficos. Se observó que hubo predominio de los estudios con enfoque geriátrico (54\%). En relación con los abordajes y el periodo analizado, hubo en la última década (1990 a 2000), un aumento, distribuyéndose en: Biológica (32\%), Recursos Humanos (18\%), Social (17\%), Psicológica $(9,8 \%)$, Holística (4,0\%), con excepción de la ética que permaneció en el mismo porcentaje en los dos periodos (0,8\%). En relación con el tipo de investigación predominó la cualitativa (49,2\%). Se concluye que las perspectivas y tendencias en relación con los ancianos indican un compromiso de los profesionales, por la necesidad de conocer las transiciones demográficas y epidemiológicas actuales y a partir de eso, planear acciones de cuidado al anciano. Se observó además, la necesidad de capacitación de recursos humanos, cuyo objetivo seria capacitar personas para el mundo del trabajo al lado de los ancianos, tanto en el ámbito domiciliario como en el profesional.

DESCRIPTORES: gerontología, geriatría, investigación

\footnotetext{
${ }^{1}$ Seminário da Disciplina: ERG: Processo de Envelhecer - enfoque da intervenção na área da saúde. Docentes responsáveis: Profas.Dras. Maria Manuela Rino Mendes e Rosalina Aparecida Partezani Rodrigues; ${ }^{2}$ Doutoranda - Área de Enfermagem Fundamental da Escola de Enfermagem de Ribeirão Preto da Universidade de São Paulo, Docente da Universidade Estadual do Ceará, Enfermeira do Instituto Dr. José Frota, e-mail: celfrei@eerp.usp.br; ${ }^{3}$ Doutoranda Área de Enfermagem Fundamental da Escola de Enfermagem de Ribeirão Preto da Universidade de São Paulo, Docente da Universidade Federal do Mato Grosso; ${ }^{4}$ Doutoranda do interunidades da Escola de Enfermagem de Ribeirão Preto da Universidade de São Paulo, Docente da Universidade Federal do Acre; ${ }^{5}$ Mestranda em Saúde Mental da Faculdade de Medicina de Ribeirão Preto da Universidade de São Paulo
} 
INTRODUÇÃO

A busca para compreender a velhice e todas as modificações decorrentes do avanço da idade teve inicio com as civilizações mais antigas, nas quais variavam o conceito de envelhecimento e a aceitação da velhice. Nos períodos que se seguiram, também surgiram novas teorias para explicar e justificar tal processo.

Atualmente, verifica-se, por meio de dados epidemiológicos, que está ocorrendo um crescimento da população idosa como conseqüência da diminuição da taxa de mortalidade e declínio da fecundidade. Essas transições afetam diretamente, e de forma significativa, a estrutura etária da população e, conseqüentemente, intensificam os problemas de uma determinada sociedade.

Os idosos, nas diferentes camadas, segmentos ou classes sociais, vivem a velhice de forma diversificada, como se o fim da vida reproduzisse e ampliasse as desigualdades sociais. Considerase, ainda, que 0 aumento da população idosa em nossa sociedade constitui-se, no momento, num problema de saúde que poderá ser ainda maior, com o decorrer do tempo. Diante disso, é preciso, além da perspectiva adotada, que as ações dos profissionais da área da saúde e das ciências humanas sejam dirigidas à transformação dessa realidade, não apenas enfocando a velhice, mas todas as fases da vida, nas suas diferentes abrangências: habitação, educação, saneamento, previdência, dentre outras ${ }^{(1)}$.

No Brasil, o crescimento da população idosa tem despertado o interesse desses profissionais para o desenvolvimento de pesquisas que abordem essa temática. Nota-se preocupação, ainda, com a necessidade de formação e capacitação de recursos humanos, fundamentada no cuidar gerontológico, para atender aos idosos, também denominados anciões, velhos ou grupo da terceira idade, para que essa fase de transformação se dê de forma digna, mesmo diante dos desafios enfrentados pela sociedade brasileira contemporânea. Os valores atribuídos a essas pessoas dependem do contexto social e cultural de cada civilização.

No que se refere a esses vocabulários classificatórios, no século XIX, na França, o termo velhice caracterizava, essencialmente, as pessoas que não podiam assegurar seu futuro financeiro, designando-se, mais precisamente, como velho, "vieux", ou velhote "vieillard", os indivíduos que não tinham status social, enquanto idoso traduzia-se "personne âgée", ou seja, aqueles que viviam socialmente bem. Reportando-se ao século XVIII, a palavra velhice não possuía conotação pejorativa, sendo empregada para designar aqueles que dispunham de bom poder aquisitivo e cuja imagem se associava a "bom pai" ou "bom cidadão". Observa-se, por conseguinte, que a velhice daquele tempo só existia para aqueles que estavam situados na camada mais rica da sociedade e podiam vender sua força de trabalho ${ }^{(2)}$
Com o aparecimento de novas políticas sociais e mudanças na estrutura social, elevam-se as pensões, o que faz aumentar 0 prestígio dos aposentados. Nessa ocasião, esses termos sofrem modificações, e volta-se um novo olhar para a pessoa velha. Surge, então, a expressão terceira idade, designando, principalmente, envelhecimento ativo e independente, mostrando, assim, essa nova etapa da vida - um novo ciclo entre a aposentadoria e a velhice ${ }^{(2)}$.

No Brasil, não existe designação específica para tais expressões, que passaram a ser utilizadas em pesquisas e também no vocabulário quotidiano, algumas vezes com conotação depreciativa, porém sem preocupação de fundamentações teóricas.

Entretanto, a resposta a qualquer tipo de questão sobre velho ou velhice, no Brasil, depende de como ela é feita e a quem é direcionada; não existe uma resposta única, porque o fenômeno da velhice tem múltiplos significados, contextualizados por fatores individuais, interindividuais, grupais e socioculturais. Afirma-se que o conhecimento científico, também contextualizado por esses fatores, desempenha um papel fundamental na atribuição de significados a esse objeto, à medida que justifica, explica e legitima determinadas práticas e atitudes em relação à velhice ${ }^{(3)}$.

O velho, portanto, nem sempre é considerado na sociedade atual, tanto que o senso comum utiliza as mais variadas expressões para designar esse grupo da população (velho, idoso, terceira idade, dentre outras), não havendo preocupação de se ajustar uma expressão adequada e única para designar as pessoas pertencentes a essa faixa etária de 60 anos ou mais ${ }^{(4)}$, prevalecendo o mito de considerar a velhice como sinal de fragilidade, decadência e/ou dependência.

Em estudos sobre envelhecimento da população brasileira, identificou-se que, na virada do século, deveria haver no Brasil, 8,7 milhões de pessoas com 65 anos, e mais, sobreviventes de coortes nascidos até 1935, o que quer dizer que $1 \mathrm{em}$ cada 20 residentes do país seria idoso e que, vinte anos mais tarde, essa relação seria 1 para 13. Portanto, deve merecer, cada vez mais, o interesse dos órgãos públicos, dos formadores de políticas sociais e da sociedade em geral, o crescimento da população idosa no país, devendo-se levar em conta, principalmente, as características demográficas, econômicas e sociais desse país. Diante dessa realidade, novas demandas por serviços, benefícios e atenções constituem-se em desafios para os governantes e para a sociedade do presente e do futuro, uma oportunidade para os idosos reescreverem sua história com novos conceitos ${ }^{(5)}$.

No Brasil, acredita-se que o processo de mudança demográfica é resultante de um complexo emaranhado de fatores econômicos, sociais, culturais, ideológicos e psicológicos, os quais vêm criando, reciprocamente, características distintas no relacionamento social em geral, seja ele familiar, profissional, voltado 
ao cuidado com os idosos, ou ao papel da mulher na sociedade, entre outros ${ }^{(6)}$.

Por outro lado, as representações do papel do idoso têmse mostrado diferentes na sociedade atual, visto que a representação da velhice, como processo de perdas, tem sofrido uma inversão, sendo essa etapa valorizada e privilegiada, tendo em vista as novas conquistas, em busca de prazer, da satisfação e da realização pessoal, o que faz da gerontologia objeto de crescente estudo. 0 aumento de oferta de programas voltados para a população mais velha e o investimento da mídia no assunto têm impulsionado esse novo mercado de consumo. Entretanto, a situação dos idosos no país mostra uma grande diversidade, propiciando a exclusão daqueles que não compartilham das mudanças atuais ${ }^{(7)}$.

0 processo do envelhecimento também está relacionado ao aparecimento de determinadas doenças, embora poucos estudos comprovem o surgimento dos fatores de risco após os 65 anos, posto que, nessa fase, alterações orgânicas, somadas às debilidades, favorecem o aparecimento de doença. Além disso, há outros fatores de risco como tabagismo, alcoolismo, associados ao aparecimento de doenças, nessa faixa etária.

Dentre as ciências, a geriatria é a que se ocupa, essencialmente, dos problemas de saúde do idoso. Essa palavra foi utilizada pela primeira vez, em 1909, por Ignaz L. Nascher, médico norte-americano e autor do primeiro livro sobre envelhecimento, publicado em 1914, sendo a geriatria, por conseguinte, uma especialidade abrangente, cujo horizonte transcende ao tratamento das doenças dos velhos, visto que a saúde deles é mais bem estimada pelo nível de independência funcional e autonomia, e não somente pela presença de um determinado agravo ${ }^{(8)}$.

Nesse sentido, os autores anteriormente citados entendem que o desafio maior da geriatria seja prevenir, tratar e cuidar daqueles que possuem os problemas típicos das pessoas de idade avançada, tais como: imobilidade, instabilidade, incontinência, insuficiência cerebral, iatrogenia e prejuízos para a independência funcional.

No entanto, percebe-se que somente a geriatria não conseguia atender os problemas comuns dos idosos, além dos relacionados à área biológica, ou seja, o processo de envelhecer, consoante os demais aspectos. A gerontologia, no início do século $X X$, preocupada em compreender esse processo dentro da perspectiva que vislumbra a pessoa na sua individualidade, passa a considerar dois enfoques, que aparecem como os mais difundidos nas pesquisas. Diante disso, conclui-se, que, para compreensão global do idoso, é imprescindível a presença de profissionais que, em equipe, se completem e implementem seus conhecimentos sobre 0 assunto.

A palavra gerontologia, introduzida por Élie Metchnikoff, em 1903, significa o estudo científico do processo de envelhecimento de todas as coisas vivas e dos múltiplos problemas que envolvem a pessoa idosa. Ela é paradoxalmente jovem, embora o envelhecimento e os clamores pelo aumento da longevidade sejam seguramente tão antigos quanto a própria civilização ${ }^{(8)}$.

Verifica-se, pois, que tanto a gerontologia como a geriatria abrigam profissionais especializados dedicados ao tratamento da velhice, sendo ela entendida como o processo de modificações que ocorre no organismo humano em relação à duração cronológica, acompanhado de alterações de comportamentos e de papéis sociais. Assim, em respeito a essa população, é necessário que se examine o lugar destinado a ela e que representação se faz dela nos diferentes tempos e lugares. Também a necessidade de preparar profissionais para melhor assistir a esse grupo de pessoas é importante. Não obstante, especialistas devem trabalhar as questões comuns do envelhecer, que se caracterizam pelas alterações biológicas, não as dissociando das necessidades sociais, psicológicas e culturais.

0 reconhecimento dessa multiplicidade de fatores e 0 estudo a respeito do idoso possibilitarão um cuidar efetivo e eficiente desses profissionais, a partir da compreensão do processo de envelhecer.

Nesse sentido, questionam-se Quais enfoques as pesquisas estão dando aos estudos dos idosos?; Quais são as tendências e perspectivas em relação à geriatria e gerontologia?; Há capacitação de profissionais para que trabalhem junto aos idosos? Quais são os não-profissionais que cuidam de idosos?

Para desenvolvimento deste trabalho, considerou-se oportuno, primeiramente, realizar um levantamento bibliográfico a fim de identificar, entre as pesquisas realizadas, que abordagens e enfoques são utilizados com mais freqüência, no atendimento aos idosos, e como é feita a capacitação de pessoas que devem desempenhar tal atividade. Também se procurou conhecer as diferentes pesquisas realizadas nesse âmbito, com o fim de responder a essas indagações. Para tanto, traçaram-se os seguintes objetivos: identificar e analisar as tendências e perspectivas nas áreas de gerontologia e geriatria, relacionadas à pesquisa.

\section{MÉTODOS}

A fim de atender aos objetivos propostos, elaborou-se um estudo exploratório descritivo, feito através de levantamento bibliográfico junto ao banco de dados LILACS e de busca em teses (doutorado, livre-docência) e dissertações catalogadas no acervo da Escola de Enfermagem de Ribeirão Preto, da Universidade de São Paulo.

Utilizaram-se para busca as seguintes palavras-chave: gerontologia, geriatria, idoso, perspectivas, tendências e pesquisas e recursos humanos. 
Os critérios para inclusão das referências bibliográficas na pesquisa foram distintos. As pertencentes ao LILACS deveriam conter as palavras-chave: geriatria e gerontologia; idoso relacionado com tendências, pesquisas e recursos humanos. Quanto ao levantamento realizado no catálogo do acervo citado, os trabalhos deveriam conter, no título, pelo menos uma das palavras-chave. Estabeleceu-se esse critério em função de se ter efetuado busca manual.

Realizou-se um corte histórico para delimitar o número de dados do estudo, incluindo-se publicações que iam desde o início dos anos 80 até os dias atuais, pela necessidade de se conhecerem e se confrontarem as tendências das referidas épocas.

Após identificação, os documentos foram agrupados por ordem cronológica, temática discutida e enfoque, facilitando, assim, a análise, o que permitiria conhecer as perspectivas das pesquisas em geriatria e gerontologia.

Ao final do levantamento, obteve-se um total de 154 artigos, e, destes, analisaram-se apenas 122 , não se considerando os demais, citados mais de uma vez no banco de dados do LILACS.

De posse do material para análise e síntese, seguiram-se as etapas ${ }^{(9)}$ descritas abaixo, quais sejam:

- Leitura exploratória e reconhecimento dos artigos que interessavam à pesquisa. Ex: o título, o resumo e a introdução.

- Leitura seletiva, escolha do material que, de fato, servia aos propósitos da pesquisa, item de natureza crítica. Ex.: observar os artigos que não se repetiam e eleger os que atendiam ao objetivo.

- Leitura analítica e análise dos textos selecionados, embora pudesse ocorrer a adição de novos artigos e a supressão de outros. Ex.: análise e categorização, com construção de tabelas e gráficos.

- Leitura interpretativa, que conferia significado mais amplo aos resultados obtidos com a leitura analítica. Nesse item, o pesquisador fixava-se nos dados e caminhava além deles, através da ligação com outros conhecimentos já obtidos. Ex: discussão dos resultados da investigação, segundo dados encontrados na análise.

Mostrou-se importante, para análise dos dados, a construção de tabelas e gráficos que imprimissem as temáticas encontradas, os enfoques mais utilizados e as abordagens encontradas nas pesquisas, como também a identificação do tipo de pesquisa mais utilizado nos dois períodos (1980 a 1989 e 1990 a 2000).

Após elaboração das tabelas, as discussões fundamentaram-se à luz da compreensão de velhice ${ }^{(4)}$. Conforme a autora, a velhice, enquanto sentido biológico, é uma realidade que transcende à história, sendo esse destino variável de acordo com 0 contexto social, uma vez que é por meio da sociedade que se conhece a representação do idoso, quer por meio de estudos científicos, quer pelo senso comum. Assim, torna-se possivel articular as diferentes representações que propiciarão 0 entendimento sobre 0 assunto.

\section{ANÁLISE E DISCUSSÃO DOS DADOS}

A análise do material estudado encontra-se nas tabelas e gráficos que expõem a distribuição da freqüência dos trabalhos e mostram as tendências dos estudos nos anos 80 e perspectivas dos anos 90 a 2000.

As tabelas e gráficos demonstram, inicialmente, quais os enfoques predominantes em cada época, se geriatria ou gerontologia, e, a seguir, a verificação de quais abordagens são mais comuns no estudo.

Tabela 1- Distribuição percentual dos artigos, segundo fonte de informações e enfoques de pesquisa, no período de 1980 a 2000. Ribeirão Preto - 2000

\begin{tabular}{|c|c|c|c|c|c|c|}
\hline \multirow[t]{3}{*}{ FONTE DE IMFORHAÇÕESS } & \multicolumn{4}{|c|}{ ENFOQUE } & \multicolumn{2}{|c|}{ TOTÁL } \\
\hline & \multicolumn{2}{|c|}{ GERONTOLOGIḰ } & \multicolumn{2}{|c|}{ GERIÁTRIÁ } & \multirow[b]{2}{*}{$\mathbf{H}^{\mathbf{D}}$} & \multirow[b]{2}{*}{$\%$} \\
\hline & $\mathrm{N}^{\mathrm{D}}$ & $\%$ & $\mathrm{~N}^{\mathbf{0}}$ & $\%$ & & \\
\hline LILACS & 40 & 32,8 & 48 & 39,0 & 88 & 72,0 \\
\hline DISSERTAÇỐES & 9 & 7,4 & 14 & 11,5 & 23 & 18,9 \\
\hline DOUTORADO & 5 & 4,0 & 3 & 2,5 & 8 & 6,5 \\
\hline LWRE-DOCÊNCIA & 2 & 1,6 & 1 & 0,8 & 3 & 2,5 \\
\hline TOTAL & 56 & 45,8 & 66 & 53,8 & 122 & 100 \\
\hline
\end{tabular}


Observou-se, em relação à fonte de informação, que no Banco de Dados Lilacs (72,0\%), houve predomínio de estudos relacionados ao enfoque geriátrico em comparação às demais fontes de informações. Isso porque esse Banco de Dados tem maior número de publicações e contempla artigos não só escritos em português, mas também em espanhol.

Do total das fontes de informações e enfoques, registrouse, nas pesquisas em geriatria, um percentual de $53,8 \%$ e de $45,8 \%$ em gerontológico.

Em relação à fonte de informações e enfoques de pesquisa, verificou-se que, tanto nas referências encontradas no Lilacs $(39,0 \%)$, como nas dissertações (11,5\%), predominou o enfoque geriátrico, com 53,8\%. Quanto às teses, os números foram: doutorado, 4,0\%, e livre docência, 1,6\%, com predomínio do enfoque gerontológico.

$\mathrm{Na}$ evolução da humanidade, observou-se um enfoque predominante no modo de enxergar a velhice, sob o ponto de vista do declínio físico e biológico, o que pode ser comprovado, pois grande parte das referências avaliadas no Lilacs e nas dissertações, tinham como enfoque a geriatria.

Embora houvesse predomínio do enfoque geriátrico, observou-se que, quando ocorreu maior graduação no nível de pesquisa (doutorado e livre-docência), em relação à velhice, predominou o enfoque gerontológico. Isso porque, quando o pesquisador tem oportunidade de realizar uma investigação mais aprofundada sobre a temática "idoso", em níveis de pós-graduação e livre-docência, tenta-se não sobrepor apenas os aspectos físicos e biológicos, ficando a pesquisa voltada à visão psicossocial e cultural. Tal fato reforça o sentido de que, na velhice, o declínio das habilidades físicas e mentais não resulta somente das conseqüências do avanço da idade, mas também dos fatores socioculturais que contextualizam o idoso.

Nesse ponto de vista, ressaltam-se a importância e as evidências das pesquisas sobre a velhice, no Brasil, com enfoque gerontológico, reafirmando a necessidade de investigações, visando reformular as representações sobre o envelhecimento no país ${ }^{(10)}$.

Enfatiza-se, ainda, que as pesquisas voltadas para 0 entendimento do processo de envelhecer afastam os estereótipos como o que considera a velhice um período de retraimento, em face da doença e da pobreza, uma situação de dependência e passividade, legitimando, assim, a visão das políticas públicas que têm o idoso como um ser doente, isolado, abandonado e alimentado pelo estado.

Dessa forma, observa-se que investir em pesquisas com essa temática favorece emergir as lacunas existentes nas políticas públicas e ações da sociedade.

Tabela 2 - Distribuição percentual de artigos, segundo ano de publicação e enfoque temático de pesquisa, período de 1980 a 2000. Ribeirão Preto - 2000

\begin{tabular}{|c|c|c|c|c|c|c|}
\hline \multirow[t]{3}{*}{ ÁNO DE PUBLICAÇão } & \multicolumn{4}{|c|}{ ENFOQUES } & \multicolumn{2}{|c|}{ TOTAL } \\
\hline & \multicolumn{2}{|c|}{ GERONTOLÓGICO } & \multicolumn{2}{|c|}{ GERÍ́TRICO } & \multirow[b]{2}{*}{$\mathbf{H}^{0}$} & \multirow[b]{2}{*}{$\%$} \\
\hline & $\mathbf{N}^{0}$ & $\%$ & $\mathbf{N}^{\mathbf{0}}$ & $\%$ & & \\
\hline 1980 a 1984 & 3 & 2,5 & 10 & 8,2 & 13 & 10,7 \\
\hline 1985 a 1989 & 4 & 3,3 & 15 & 12,3 & 19 & 15,6 \\
\hline 1990 a 1994 & 10 & 8,2 & 12 & 9,8 & 22 & 18,0 \\
\hline 1995 a 2000 & 39 & 32,0 & 29 & 23,8 & 68 & 55,7 \\
\hline TOTALL & 56 & 46,0 & 66 & 54,0 & 122 & 100 \\
\hline
\end{tabular}

Em geral, verificou-se um aumento crescente das publicações/trabalhos apresentados no período de 1980 a 2000, mesmo tendo o último intervalo estudado um ano a mais.

$\mathrm{Na}$ associação do período das publicações com os enfoques, constaram os seguintes resultados: nos intervalos de 1980 a $1984,8,2 \%$; 1985 a $1989,12,3 \%$; e de 1990 a $1994,9,8 \%$, predominando o enfoque geriátrico no total da amostra. No entanto, observou-se que, no último intervalo, de 1995 a 2000, o enfoque gerontológico foi maior $(32,0 \%)$ em relação ao geriátrico $(23,8 \%)$, fato que pode estar associado às pesquisas demográficas e epidemiológicas, que ressaltam a importância de investigar o tema "idoso".

$O$ aumento das pesquisas voltadas às diferentes dimensões do problema do envelhecimento, na última década, enfatizou a necessidade de se dedicar mais atenção ao enfoque gerontológico. Com relação a essa questão, o Decreto N. ${ }^{0} 1.948$ de 03 de julho de 1996, regulamentou a Política Nacional do Idoso, com competência não só para as questões da doença, como também à promoção da saúde do idoso ${ }^{(10)}$. 
Tabela 3 - Distribuição percentual dos artigos estudados, segundo período e área de abordagem, 1980 a 2000. Ribeirão Preto - 2000

\begin{tabular}{|c|c|c|c|c|c|c|}
\hline \multirow{2}{*}{$\begin{array}{l}\text { ABBORDÁGENSIAHOS DE } \\
\text { PUBLICAÇÃ̃o }\end{array}$} & \multicolumn{2}{|c|}{1980 a 1989} & \multicolumn{2}{|c|}{1990 a 2000} & \multicolumn{2}{|c|}{ TOTALL } \\
\hline & $\mathrm{N}^{0}$ & $\%$ & $\mathbf{H}^{0}$ & $\%$ & $\mathbf{N}^{0}$ & $\%$ \\
\hline $\begin{array}{l}\text { BIOLÓGICA } \\
\text { PSICOLÓGICA } \\
\text { SOCIAL } \\
\text { HOLISTCA } \\
\text { ÉTCA } \\
\text { RECURSOSHUMANOS } \\
\text { TOTÁL }\end{array}$ & $\begin{array}{l}10 \\
1 \\
6 \\
2 \\
1 \\
2 \\
22\end{array}$ & $\begin{array}{c}8 \\
0,8 \\
5 \\
1,6 \\
0,8 \\
1,6 \\
17,8\end{array}$ & $\begin{array}{c}39 \\
12 \\
21 \\
5 \\
1 \\
22 \\
100\end{array}$ & $\begin{array}{c}32 \\
9,8 \\
17,2 \\
4,2 \\
0,8 \\
18 \\
82\end{array}$ & $\begin{array}{c}49 \\
13 \\
27 \\
7 \\
2 \\
24 \\
122\end{array}$ & $\begin{array}{c}40 \\
10,7 \\
22,1 \\
5,7 \\
1,6 \\
19,7 \\
100\end{array}$ \\
\hline
\end{tabular}

Pela Tabela 3, observa-se que, em relação às abordagens e ao período analisado, houve, na última década (1990 a 2000), aumento das diferentes abordagens, como a Biológica (32\%), Recursos Humanos (18\%), Social $(17,2 \%)$, Psicológica $(9,8 \%)$, Holística (4,0\%), e, excetuando-se, Ética, temática que permaneceu com o mesmo percentual nos dois períodos $(0,8 \%)$.

$\mathrm{Na}$ área Psicológica, as alterações emocionais decorrentes do envelhecimento não são mais vistas como conseqüência da idade, o que tem aumentado o número de pesquisas que buscam afastar o estereótipo de que velhice e alterações psicológicas não estão associadas.

A esse respeito, considera-se a Psicologia do Envelhecimento como uma área emergente, explanando sobre suas origens e contextualizando o desenvolvimento e o envelhecimento, segundo uma perspectiva teórica de curso de vida. Além disso, a autora coloca que um envelhecimento bem-sucedido depende de um conjunto de elementos e ressalta, principalmente, as perspectivas individuais e as socioculturais ${ }^{(11)}$.

Quanto à formação de Recursos Humanos direcionada ao idoso, a Tabela 3 mostra ascensão nas investigações relacionadas a esse tema, causada, talvez, pelo aumento da expectativa de vida dessa população e pelo aparecimento das doenças crônicodegenerativa.

Nesse sentido, acredita-se que o avanço das novas e nãoinvasivas tecnologias propedêutico-diagnósticas não veio acompanhado, com a mesma agilidade, por inovações terapêuticas livres de reações adversas importantes para as doenças que mais afetam as pessoas idosas, mesmo considerando-se a grande quantidade de novos fármacos que são freqüentemente testados e comercializados, em especial para o uso cardiovascular e psiquiátrico $^{(12)}$.

Essa situação desencadeou maior procura pelos serviços de saúde e, consecutivamente, gerou aumento nos gastos públicos. Para atender a essa demanda, as pesquisas e ações públicas, por meio de novas estratégias, buscam melhorar a qualidade de vida dos idosos investindo em novas tecnologias, formação e qualificação de recursos profissionais. Isso ocorre tanto que a Política Nacional do Idoso, Lei 8.843/1994, dá competência ao Ministério de Previdência e Assistência Social para organizar e promover a capacitação de profissionais interessados em atender a população, devendo estes viabilizarem, também, o treinamento de cuidadores domiciliares, com fins de envolver e obter a cooperação das famílias na continuidade de cuidados.

Nesse sentido, enfatiza-se a importância e a necessidade de apoiar e treinar cuidadores familiares, uma vez que os mesmos irão, algumas vezes, continuar os cuidados ou supervisioná-los, no domicílio.

Em relação à abordagem Biológica, acredita-se que 0 aumento obtido no período de 1990 a 2000, comparado ao da primeira década estudada, pode estar associado às alterações biológicas do idoso, tendo as pesquisas demonstrado inexistência de correlação entre idade e doença na velhice.

Observa-se, ainda, a necessidade que se tem de reforçar tal idéia, afirmando que a imagem de uma sociedade em que a velhice deixa de ser um problema está em conformidade com estudos sobre outros grupos etários, que tendem a mostrar que as idades já não são definidores das formas de controle social ${ }^{(10)}$.

Embora os efeitos do envelhecimento sejam múltiplos e complexos, eles podem, por vezes, ser modificados. Sendo assim, devem-se reconhecer as principais mudanças associadas ao envelhecimento biológico; retardar os seus efeitos negativos; ou diminuir o seu alcance e evitar as complicações, mantendo uma vida higiênica e revitalizante para o organismo do idoso ${ }^{(13)}$.

Nesse aspecto, as pesquisas têm dado ênfase à importância da promoção da saúde através da educação para 0 autocuidado, possibilitando a autonomia e a independência do idoso, atendendo, dessa forma, às questões éticas necessárias na assistência a essa população, reconhecidas tanto através das pesquisas quanto da formação de recursos humanos. 
Tabela 4 - Distribuição percentual dos artigos estudados, segundo tipo de pesquisa realizada no período de 1980 a 2000 e ano de publicação. Ribeirão Preto - 2000

\begin{tabular}{|c|c|c|c|c|c|c|c|c|}
\hline \multirow[t]{2}{*}{ ANO DE PUBLICAÇÃo } & \multicolumn{2}{|c|}{ QUALITATYYA } & \multicolumn{2}{|c|}{ QUANTITATNA } & \multicolumn{2}{|c|}{ SEH ESPECIFICAÇÃO } & \multicolumn{2}{|c|}{ TOTÁL } \\
\hline & $\mathbf{N}^{\mathbf{D}}$ & $\%$ & $\mathbf{N}^{\mathbf{D}}$ & $\%$ & $\mathrm{~N}^{\mathrm{D}}$ & $\%$ & $\mathbf{H}^{0}$ & $\%$ \\
\hline $\begin{array}{l}1980 \text { a } 1984 \\
1985 \text { a } 1989 \\
1990 \text { a } 1994 \\
1995 \text { a } 2000 \\
\text { TOTaL }\end{array}$ & $\begin{array}{l}- \\
- \\
21 \\
39 \\
60\end{array}$ & $\begin{array}{c}- \\
- \\
17,2 \\
32,0 \\
49,2\end{array}$ & $\begin{array}{l}1 \\
2 \\
11 \\
33 \\
47\end{array}$ & $\begin{array}{l}0,8 \\
1,6 \\
9,0 \\
27,0 \\
30,4\end{array}$ & $\begin{array}{c}- \\
5 \\
7 \\
3 \\
15\end{array}$ & $\begin{array}{c}- \\
4,0 \\
5,7 \\
2,5 \\
12,2\end{array}$ & $\begin{array}{c}1 \\
7 \\
39 \\
75 \\
122\end{array}$ & $\begin{array}{l}0,8 \\
5,7 \\
32,0 \\
61,5 \\
100\end{array}$ \\
\hline
\end{tabular}

Apesar de não se terem identificado os aspectos metodológicos em toda a amostra da investigação, observou-se que, na primeira década, as referências apresentaram predomínio da abordagem quantitativa, 2,4\% do total, excluindo-se as referências sem especificações.

$\mathrm{Na}$ segunda década, encontrou-se a abordagem quantitativa, com $38,4 \%$, e a qualitativa, com $49,2 \%$, embora alguns autores não tenham especificado, em seus resumos, o tipo de pesquisa que realizaram; nesse caso, esse grupo ficou sem especificação, somando $12,2 \%$ do total.

A abordagem qualitativa referente à temática do idoso, nas pesquisas das últimas décadas, tem mostrado outra perspectiva em relação a essa população, nas diversas dimensões.

As pesquisas de cunho qualitativo realizadas com grupos de idosos mostraram que essa população projetava uma imagem otimista da velhice e diferente daquela preconizada pelos mitos. Essa perspectiva revela a representação da velhice, sob o ponto de vista dos depoimentos dos próprios idosos, o que possibilita ao pesquisador perceber e discutir outras questões de ordem psico-sócio-cultural e conhecer a amplitude não contemplada nas pesquisas quantitativas.

\section{CONCLUSÃO}

$\mathrm{Na}$ trajetória desta investigação, observou-se que o significado do envelhecimento está intimamente ligado ao contexto social e que a representação que se faz dele é cultural, ou seja, cada sociedade, de acordo com o tempo, atribui valores e interesses diferentes à pessoa do idoso, à temática velhice e, conseqüentemente, ao processo de envelhecer.

Conforme demonstraram as tabelas e gráficos, as pesquisas revelam que a velhice é, inicialmente, despertada sob a ótica geriátrica, no entanto, a partir dos anos 90 , é que se despertou o entendimento para as questões da gerontologia, como também as sociais, psicológicas e éticas, todas voltadas ao estudo do idoso e, conseqüentemente, à velhice, período em que demonstrou considerável ascensão, nos trabalhos encontrados.

As pesquisas têm salientado, ainda, a necessidade da capacitação de recursos humanos para assistência a essa população, tanto no âmbito profissional como no domiciliar, devido à grande demanda dessa clientela aos serviços de saúde, fato ressaltado pelos estudos da transição demográfica e epidemiológica. Salientam, também, a necessidade de se implementarem serviços de promoção à saúde, preservação da vida e recuperação de doenças, de modo que a qualificação de pessoas para cuidar de idosos, reflita-se no desempenho do cuidado, na atenção à manutenção da autonomia e à independência das pessoas que envelhecem.

Nesse sentido, as instituições de ensino superior, centro formadores de opiniões e profissionais, vêm trabalhando através de grupos de estudo, pesquisa com idosos e familiares, no domicílio. Essa temática também é implementada nos cursos de graduação e pós-graduação que, além de utilizarem pesquisas, investem na subjetividade dos idosos, tendo em vista o processo de envelhecer e a velhice. Acredita-se que tal interesse possibilite mudanças na representação dos idosos na sociedade, demonstradas pelo direcionamento dos focos de pesquisas cujas visões estão mais voltadas ao processo de envelhecer, senescência, com fins de compreender a senilidade e, com isso, poder desenvolver ações para se cuidar do idoso. E ainda, quanto ao senso comum, que possibilite ampliar a dimensão do conceito sobre o significado de velho, velhice e processo de envelhecer.

Dessa forma, vislumbra-se que os profissionais de saúde possam identificar, nas pesquisas divulgadas, os seguintes dados relacionados aos idosos: clareza a respeito das transições demográficas e epidemiológicas para, assim, influenciarem no planejamento e na tomada de decisão na área de saúde, favorecendo encontros, divulgando pesquisas realizadas e desenvolvendo ações voltadas a essa população, baseadas no conhecimento científico para o entendimento do idoso. Quanto às políticas de saúde, estas devem ir além das discussões teóricas, sendo mais efetivas, levando-se em conta a situação particular de cada região e o contexto de cada idoso, sem esquecerem as dimensões éticas, cada vez que algum profissional se propuser a desenvolver uma pesquisa ou cuidar de um idoso. As pesquisas devem, ainda, possibilitar ações necessárias e adequadas às transformações sociais, com vistas a beneficiarem os idosos. 


\section{REFERÊNCIAS BIBLIOGRÁFICAS}

1. Haddad EGM. A velhice em movimento. Gerontologia 1993; 1(1)2930.

2. Peixoto $C$. Entre o estigma e a compaixão e os termos classificatórios: velhos, velhote, idoso, terceira idade. In: Moraes M, Barros L, Debert G, Peixoto C. Velhice ou terceira idade?. Rio de Janeiro: Fundação Getúlio Vargas; 1998. p. 69-84.

3. Neri AL. Envelhecer num país de jovens - significados de velhos e velhice segundo brasileiros não idosos. Campinas (SP): Editora da Unicamp; 1991.

4. Beauvoir S. A velhice. Rio de Janeiro: Nova Fronteira; 1990.

5. Berquó E. Considerações sobre envelhecimento da população no Brasil. In: Neri AL, Debert GG, Berquó E, Oliveira MC, Simões JÁ, Cachioni M, et al. Velhice e sociedade. São Paulo (SP): Papirus; 1999. p.11-40.

6. Patarra NL. Mudanças na dinâmica demográfica. In: Monteiro CA, Patarra NL. Velhos e novos males da saúde do Brasil. São Paulo (SP): Hucitec; 1995. p.61-78.

7. Debert GG. Antropologia e o estudo dos grupos e das categorias. In: Moraes M, Barros L. Velhice ou terceira idade?. Rio de Janeiro: Fundação Getúlio Vargas; 1998. p.49-67.
8. Papaléo-Netto M. Envelhecimento: desafio na transição do século. In: Papaléo-Netto M, Ponte JR, Duarte, ALN, Ribeiro A, Cervado AM, Donato AF, et al. Gerontologia - a velhice e o envelhecimento em visão globalizada. São Paulo (SP): Atheneu; 1996. p. 3-12.

9. Gil AC. Como elaborar projetos de pesquisa. São Paulo (SP): Atlas; 1991.

10. Debert GG. Pressupostos da reflexão antropológica sobre envelhecimento. In: Debert GG, Simões JÁ, Featherstone M, Cohen L. Textos didáticos-Antropologia e velhice. Campinas (SP): IFCH/ UNICAMP; 1998. p. 7-27.

11. Neri AL. Psicologia do envelhecimento. Temas selecionados na perspectiva do curso da vida. Campinas (SP): Papirus; 1995.

12. Lessa I. Epidemiologia das doenças crônicas não transmissíveis versus terceira idade. In: Lessa I, Hage EC, Mendonça GAS, Bloch KV, Franco LJ, Teixeira MTB. Adulto brasileiro e as doenças da modernidade - epidemiologia das doenças crônicas não transmissíveis. São Paul (SP): Hucitec; 1998. p. 203-22.

13. Berger $L$. Aspectos biológicos do envelhecimento. In: Berger $L$, Mailloux-Poirier D. Pessoas idosas - uma abordagem global. Lisboa (Portugal): Lusodidacta; 1995. p.123-45. 